\title{
Los límites de la subordinación ${ }^{*}$
}

\author{
The limits of subordination
}

\author{
José María Brucart Marraco \\ Universitat Autònoma de Barcelona \\ josepmaria.brucart@uab.cat \\ ORCID iD: 0000-0002-0514-2783
}

Recibíu / Received: 29-IX-2018

Aceptáu / Accepted: I2-XII-20I8

RESUMEN. El objetivo de este trabajo es estudiar la génesis del concepto de 'oración subordinada' y su encaje en las teorías sintácticas actuales. Se trata de un concepto relativamente tardío en la historia gramatical occidental, pues solo a partir de la Grammaire de Port-Royal (I660) tiene un desarrollo propio. Su estatus actual, por otra parte, es paradójico. Por un lado, es un término usual en las descripciones gramaticales. Pero, por otro, para las teorías contemporáneas - especialmente las de base formalista- no es un concepto primitivo, sino una mera etiqueta descriptiva. Desde el punto de vista formal, el estudio de la subordinación es el de los nexos que introducen las oraciones subordinadas y las dependencias que estos crean. La segunda parte del trabajo se dedica a estudiar los problemas existentes a la hora de establecer los límites de las oraciones subordinadas y las contradicciones que surgen al considerar las tres clases de subordinadas que la tradición ha consagrado, especialmente en lo referente a las llamadas subordinadas adverbiales.

Palabras clave: subordinación, nexos subordinantes, ensamble interno, ensamble externo.

ABSTRACT. The goal of this paper is to study the origin of the concept of 'subordinate clause' and its use in current syntactic theories. This is a relatively late concept in western grammatical tradition, given that it has only received a proper development since Port-Royal's Grammaire (I660). On the other hand, for contemporary theories - especially those of formalist orientation- it is not a primitive concept, but a mere descriptive term. From a formalist point of view, the study of subordination involves the analysis of the units that introduce subordinate clauses and the dependencies that they create. The second part of the paper is devoted to the problems that arise in the classification of subordinate clauses and in the distinction of the three types of subordinate clauses traditionally identified, especially as far as the so-called adverbial subordinate clauses is concerned.

Keywords: subordination, complementizers, internal merge, external merge.

Cómo CitAR / Form of CitATion: Brucart Marraco, José María (2019): "Los límites de la subordinación", Glosema, I, pp. 53-82. https://doi.org/I0.178 I I/glosema. I.2019.53-82.

\footnotetext{
* La investigación relativa a este trabajo ha sido financiada por los proyectos FFI2017-87140 (Redes de variación microparamétricas en las lenguas románicas), del MINECO, y 2017SGR634, de la AGAUR.
} 


\section{INTRODUCCIÓN}

$\mathrm{E}$ L título de este trabajo es ambiguo a sabiendas ${ }^{1}$. En efecto, la noción de 'límite' sugiere primariamente la de linde o frontera, pero también puede asociarse, en un sentido traslaticio, con la de limitación o insuficiencia. Mi intención es centrarme en la primera acepción, aunque también trataré episódicamente de la segunda. En particular, organizaré el trabajo en torno a cuatro apartados fundamentales. En el que sigue a esta introducción, estudiaré la génesis del concepto de oración subordinada en la tradición gramatical. En el tercero, trataré de su engarce en algunas teorías contemporáneas. El cuarto apartado se dedicará a considerar algunos de los problemas que se plantean respecto de los límites entre las principales y las subordinadas. Finalmente, en el quinto trataré de subdivisiones que la tradición ha establecido entre las distintas subclases de subordinadas y estudiaré algunas construcciones cuya acomodación respecto a ellas resulta problemática.

Soy consciente de que el tema que me propongo tratar es de dimensiones oceánicas y que puede parecer extremadamente pretencioso analizarlo con el mínimo detalle necesario en el espacio del que dispongo. Conviene, por lo tanto, dimitir ya de cualquier aspiración de exhaustividad y señalar que tan solo pretendo reflexionar sobre algunos aspectos del problema que considero relevantes. En este sentido, puede decirse que el trabajo plantea muchas más incógnitas de las que resuelve. Antes de entrar en materia, añadiré una última cautela metodológica, referida a la orientación teórica utilizada a lo largo de la exposición: el marco básico de descripción que adoptaré es el del modelo generativo, pero mi objetivo esencial no es mostrar las fortalezas o debilidades de ninguna teoría en relación con el problema estudiado, sino más bien analizar el encaje que el concepto tradicional de 'oración subordinada' tiene en ellas. En este sentido, coincido con Gutiérrez Ordóńez (I999: 49) cuando en un estudio dedicado precisamente al análisis crítico de la noción que nos ocupa, señalaba: "[...] someter de vez en cuando a una reflexión crítica los conceptos fundamentales de la teoría es una actividad que se justifica por sí misma”.

\section{El CONCEPTO DE 'ORACIÓN SUBORDINADA' EN LA TRADICIÓN GRAMATICAL}

\section{I. La aportación de Port-Royal}

Si se atiende al frecuente uso que en los manuales pedagógicos y en la mayor parte de los tratados gramaticales tiene el término de oración subordinada, se diría que

\footnotetext{
${ }^{1}$ Agradezco los comentarios y las observaciones de dos revisores anónimos, que han permitido afinar algunos aspectos de la argumentación y añadir algunas referencias indebidamente omitidas en la primera versión.
} 
denota un concepto básico y bien asentado en la disciplina. Sin embargo, cuando se estudia su génesis y evolución en la tradición gramatical de Occidente, se observa que su desarrollo es bastante tardío. Ello se debe sin duda a la concepción tradicional de la gramática como estudio de las partes de la oración. Como señala Padley (i 988: 225) en su monumental estudio sobre la teoría gramatical en los siglos XVI y XVII, "[i]n Spain as elsewhere, there is in the fifteenth and sixteenth centuries no syntax of the proposition as a whole".

El mismo autor (Padley 1988: 296) señala como excepción a esta tendencia general la Teütsche Grammatica (c. I 534) del alemán Valentin Ickelsamer, que dedica media docena de páginas a la sintaxis oracional y plantea algunas cuestiones que atañen a la oración compleja. La obra fue criticada por algunos gramáticos del XVII que consideraban que su enfoque era más retórico que gramatical. No resulta extraño que el autor tomara esta orientación a la hora de abordar el estudio de la oración, si se tiene en cuenta la mayor extensión de las unidades utilizadas por la retórica frente al enfoque atomístico tradicionalmente aplicado en la gramática.

No obstante, será el impulso lógico que adopta la gramática a partir del siglo XVII lo que llevará a otorgar progresivamente mayor importancia a los fenómenos oracionales, ya que tal enfoque atribuía un mayor protagonismo a la noción de 'proposición', contrapunto lingüístico del juicio lógico. El punto culminante de la tendencia a abordar los aspectos oracionales más allá de la morfosintaxis lo representa la Grammaire générale et raisonnée de Port-Royal (Arnault y Lancelot I754 [I660]), pero existen algunos antecedentes ilustres, entre los que destaca el Brocense. Breva-Claramonte (I983: 22I) señala el protagonismo que la perspectiva oracional adquiere en la Minerva (I 562 y I 587): "For Sanctius, the smallest working unit in language is sentence, since a word by itself denotes nothing unless it is part of a sentence" (Breva-Claramonte 1983: 221). La afirmación anterior podría calificarse de excesivamente contundente, pues al fin y al cabo la ordenación interna de la Minerva sigue reproduciendo en lo esencial el patrón dispositivo basado en el estudio de las partes de la oración, pero es cierto que la perspectiva oracional está muy frecuentemente en la base de la principal aportación teórica del Brocense: la incorporación a la gramática de la elipsis como mecanismo de regularización sintáctica. Tal sucede, por ejemplo, cuando el autor afirma que la conjunción copulativa une siempre oraciones, por lo que en casos como Cicero scribit et vigilat o Cicero et filius ualent (Sánchez de las Brozas I976 [1587]: III, I4) debe suponerse que se ha producido la elipsis de alguno de los miembros de oración: en el primer caso el sujeto de la segunda oración ('Cicero scribit et Cicero vigilat') y en el segundo el predicado de la primera ('Cicerus ualet et filius ualet'). 
Pero es sin duda la Grammaire génerale et raisonnée de Port-Royal (Arnault y Lancelot 1754 [1660]) el texto que marca de modo más evidente el cambio de enfoque de los estudios gramaticales hacia un mayor protagonismo de la sintaxis. En el primer capítulo de la segunda parte de la obra, antes del desarrollo de las partes de la oración, se expresa de forma palmaria la relevancia que los autores confieren a la noción de 'proposición'. Según Arnault y Lancelot, de las tres operaciones que los filósofos atribuyen al espíritu humano — concebir, juzgar y razonar-, tan solo atañen a la gramática las dos primeras, ya que el razonamiento no es sino una concatenación de juicios y su estudio atañe más propiamente a la lógica. A su vez, la operación de concebir (relacionada con los conceptos individuales) puede interpretarse como una parte de la de juzgar:

[...] car les hommes ne parlent guére pour exprimer simplement ce qu'ils conçoivent; mais c'est presque toujours pour exprimer les jugements qu'ils font des choses qu'ils conçoivent. (Arnault y Lancelot I754 [1660]: 57)

La unidad que corresponde al juicio es la proposición, que resulta de la unión de un sujeto y un predicado. La prioridad otorgada a la proposición en la descripción gramatical, no obstante, tampoco se traduce en un cambio drástico en la estructura de la obra: tras esta introducción, la Grammaire... sigue el esquema expositivo basado en las partes de la oración y dedica solo seis páginas al capítulo de la sintaxis. De ahí que Rojo (200 I: 68) señale que, a este respecto, Port-Royal, el Brocense o Nebrija no presentan diferencias insalvables:

Dentro de lo que entendemos por gramática en sentido estricto - esto es, morfología y sintaxis- la unidad básica es la palabra y, con ciertas diferencias entre ellos, la oración está presente, pero, en realidad, juega un papel muy limitado, ya que lo que - a nuestro modo de ver- sucede dentro de la oración (el desempeño de funciones como sujeto, predicado y complementos) es visto y explicado casi siempre como el resultado de las relaciones entre palabras. Por supuesto, hay referencias explícitas a funciones oracionales, pero hay que reconocer que, en general, no llegan a presentar realmente este carácter y se quedan más bien en relaciones entre palabras (el sustantivo -en nominativo- y el verbo, el verbo y el sustantivo - en caso oblicuo-, etc.) que, eso sí, tienen lugar en el interior de la oración.

De cualquier modo, la distancia entre Port-Royal y sus antecesores es considerable, ya que la primacía otorgada a la proposición —en consecuencia, a una visión que trasciende la orientación morfosintáctica dominante hasta aquel momento- se pone de manifiesto en muchos pasajes de la obra. Una de las consecuencias más ostensibles del nuevo enfoque es la definición del concepto de 'proposición incidente', antecedente inmediato del de 'oración subordinada', al afrontar el estudio de 
los pronombres relativos: para Port-Royal lo propio del relativo es hacer que la proposición a la cual pertenece pueda formar parte del sujeto o del atributo de la proposición principal:

La $2^{\mathrm{e}}$ chose que le Relatif a de propre, \& que je ne sache point encore été remarquée par personne, est que la proposition dans laquelle il entre, (qu'on peut appeler incidente) peut faire partie du sujet ou de l'attribut d'une autre proposition, qu'on peut appeler principale. (Arnault y Lancelot I754 [i660]: I09-I I0)

Nótese que la explicación no se limita a señalar la dependencia del relativo con el antecedente nominal, derivada de la naturaleza pronominal que asigna toda la tradición a esta clase de palabra (característica que la obra que nos ocupa menciona como primera propiedad de los relativos), sino que se establece de modo inequívoco su segunda función como nexo subordinante de una oración que se integra en la principal. Este es también un hallazgo feliz que, desgraciadamente, buena parte de la tradición posterior no tendrá en cuenta: la subordinada no es un elemento disjunto de la principal, sino que está incluida en ella. La postura de los maestros de Port-Royal es en este aspecto inequívoca, aunque algunos historiógrafos como Donzé (1970 [1967]: I 50) han criticado ciertas vacilaciones en su formulación. Sea como fuere, puede decirse sin ningún tipo de hipérbole que el capítulo noveno de la segunda parte de Port-Royal, dedicado al relativo, representa una de las cimas en la historia de la teoría gramatical, como lo es también la teoría de la determinación nominal presente en la obra ${ }^{2}$.

La noción de 'proposición incidente' se aplica igualmente en la Grammaire... a las completivas introducidas por que, a partir de la idea de que esta conjunción procede de la gramaticalización del relativo - una teoría, por cierto, defendida por autores contemporáneos de diversa orientación, como Kayne (1976) y Muller $\left(\right.$ I996) ${ }^{3}$-; a las interrogativas indirectas encabezadas por un pronombre o adverbio de esa clase, y al infinitivo, que se interpreta también como un caso especial de elemento que introduce una proposición incidente:

[...] on demande ce que c'est proprement que l'infinitif, lorsqu'il n'est point nom \& qu'il retient son affirmation, comme dans cet exemple, Scio malum esse fugiendum. Je ne sais si personne a remarqué ce que je vas dire : c'est qu'il me semble que l'infinitif est entre les autres manieres du verbe, ce qu'est le relatif entre les autres pronoms. Car, comme nous avons dit que le relatif a de plus que les autres pronoms, qu'il joint la proposition dans laquelle il entre à une autre proposition, je crois de même que l'infinitif a, par-dessus l'affirmation du verbe, ce pouvoir de joindre la proposition où il est à une autre. (Arnault y Lancelot I754 [1660]: I 58)

\footnotetext{
${ }^{2}$ Para un estudio de las relaciones entre la lógica y la gramática en Port-Royal, $c f$. Pariente I984 y I985, y Dominicy I 984.

${ }^{3} Y$ también presente en la tradición gramatical española: Gómez Hermosilla i84I [I835].
} 
Para justificar la idea de la vinculación del que relativo y del completivo se aduce la existencia de las oraciones de relativo con duplicación mediante un pronombre reasuntivo en el interior de la subordinada (es decir, el patrón Es un libro que no lo lee nadie), una clase de construcciones que ha suscitado considerable interés en la investigación más reciente (tanto en adquisición como en la teoría gramatical) ${ }^{4}$.

A Port-Royal pertenece también la distinción entre proposiciones compuestas y complejas, aunque el desarrollo de estos conceptos no se lleva a cabo en la Grammaire..., sino en La Logique, ou l'art de penser, publicado en 1662 por uno de los autores de la gramática, Antoine Arnault, y por Pierre Nicole (I 992 [I662]). Entre las compuestas se incluyen las condicionales, las causales y las adversativas (denominadas en la obra "discretivas"). Por lo tanto, estas proposiciones no se consideran incidentes, sino ligadas a la principal por medio de conjunciones que expresan el tipo de relación lógica que existe entre ellas. Que esta clase de construcciones no se estudiaran con mayor detalle en la Grammaire... se debe probablemente a que el tipo de relación que ejemplifican está vinculado con la operación de "razonar", que los autores consideraban más propia de la lógica que de la gramática, como se ha visto ${ }^{5}$.

Hemos estudiado con algún detalle las propuestas de Port-Royal porque en ellas está el germen del interés que la tradición posterior dedicará a la subordinación. Así, cuando Humboldt proponga en I 836 las bases para una clasificación tipológica de las lenguas, las unidades sobre las que articulará su análisis serán tres: el verbo, como núcleo de la predicación; la conjunción, como elemento que expresa la relación entre dos cláusulas, y el pronombre relativo, como unidad que desempeña simultáneamente la función de pronombre y conjunción. Resulta interesante comprobar que las dos últimas clases están íntimamente ligadas con la noción de subordinación.

\subsection{Enfoques holisticos y analiticos en el estudio de la oración}

Un aspecto no considerado hasta ahora, pero que resulta necesario mencionar para enmarcar debidamente los límites del concepto que estamos estudiando, es la relación entre la oración subordinada y la oración a secas. Como ha señalado Graffi en su detallado estudio sobre la evolución de la sintaxis desde el siglo XIX, la caracterización de la oración en toda la tradición occidental oscila entre las dos propieda-

\footnotetext{
${ }^{4}$ En relación con el español, $c f$., por ejemplo, Lope Blanch I984, Trujillo I 990 y Fernández Soriano I 995.

${ }^{5}$ De todos modos, no debe olvidarse la íntima conexión entre ambas disciplinas para los gramáticos de Port-Royal, de acuerdo con sus presupuestos racionalistas. Como señalan en el título del primer capítulo de la segunda parte de la obra, "la connoissance de ce qui se passe dans notre esprit est nécessaire pour comprendre les fondements de la Grammaire" (Arnault y Lancelot I754 [I660]: 55).
} 
des que asignaba a esta unidad la definición de Dionisio de Tracia y que se transmiten a Occidente a través de Prisciano: "Oratio est ordinatio dictionum congrua, sententiam perfectam demonstrans" (Prisciano, Institutiones grammaticae, II: 4. I 5 ; apud Graffi 200I: II3).

Graffi (200 I: I I I) distingue en la anterior definición dos partes. La primera (que denomina "analítica") alude a su carácter composicional y a la especificidad de su estructura interna. La segunda (que califica de "holística") remite a su valor interpretativo global como unidad comunicativa dotada de independencia sintáctica y semántica. Como señala el lingüista italiano, buena parte de la discusión gramatical sobre la oración incide sobre cuál de los dos enfoques debe primar. Es este un capítulo sustancial de la historia de la gramática sobre el que no podemos detenernos aquí. Nos limitaremos a señalar que, si la visión holística se impone sobre la analítica, las fronteras de la oración pueden llegar a ensancharse considerablemente. En efecto: en su versión más prototípica, la perspectiva analítica suele establecer como condición necesaria para que una secuencia pueda ser etiquetada como oración la de que exista un sujeto y un predicado con el verbo en forma personal o que tal estructura se obtenga por medio de procesos de elipsis. Por el contrario, el enfoque holístico se centra en la naturaleza independiente de la oración como unidad de comunicación. Ambos enfoques no son equivalentes. De hecho, algunos gramáticos que toman como criterio básico el enfoque holístico admiten el carácter oracional de los fragmentos, enunciados que no presentan la estructura bipartita sujeto-predicado, pese a no proponer para ellos procesos de recuperación por medio de elipsis o catálisis. Jespersen (I924), Gardiner (I95 I [1932]) o Bloomfield (I933), y en nuestra tradición Lenz (I920) o — de modo mucho más matizado- Fernández Ramírez (I986 [I95 I], vol. 4, cap. II) admiten la existencia de oraciones sin verbo: "No particular grammatical form is required for a word or a group of words to be called a sentence" (Jespersen 1924: 308).

Lo que interesa señalar aquí para nuestro propósito es que el concepto de 'oración subordinada' nace dentro de la perspectiva analítica de la oración, ya que desde la concepción holística las subordinadas no pueden ser consideradas formas sintácticamente autónomas. Una consecuencia directa de ello es la asimetría que se indica en el siguiente esquema, en donde se clasifica la unidad que aparece en cursiva según cada uno de los dos criterios:

\begin{tabular}{l|c|c} 
& ENFoque HOLÍsTico & ENFOQUE ANALítico \\
\hline a. Oyó que María se quejaba & oración & oración \\
\hline b. Oyó la queja de María & oración & oración \\
\hline c. Oyó que María se quejaba & oración subordinada & oración subordinada \\
\hline
\end{tabular}




\begin{tabular}{l|c|c} 
& ENFOQUE HOLÍsTico & ENFOQUE ANALítico \\
\hline d. Oyó la queja de María & grupo nominal & grupo nominal \\
\hline e. La queja de María & fragmento / oración & grupo nominal \\
\hline f. Que María se quejaba & fragmento / oración & oración subordinada \\
\hline
\end{tabular}

CuAdro i. Asimetrías de análisis entre ambos enfoques

Del cuadro anterior interesan especialmente los dos últimos apartados. Para algunos gramáticos — como Bloomfield (I933), que es el principal abanderado de este enfoque-, el concepto fundamental desde la perspectiva holística es el de 'independencia distribucional', de modo que La queja de María puede etiquetarse como oración en (e), puesto que aparece como única realización del correspondiente enunciado - por ejemplo, como respuesta a una pregunta del interlocutor-. No lo es, en cambio, en (d), dado que está incluido en un enunciado más amplio. Ahora bien: en este último contexto, podríamos preguntarnos por qué los autores que admiten la naturaleza oracional de esta secuencia en (e) no le asignan la etiqueta de oración subordinada en (d), de forma paralela a lo que sucede en (c) con el complemento directo de oír, una incoherencia que han señalado Rojo (I978) y Gutiérrez Ordóñez (I999). La explicación más plausible es que el concepto de 'oración subordinada' tiene su génesis en el seno de la tradición analítica y se asocia, por lo tanto, con una disposición interna bimembre sujeto-predicado de la que la queja de María carece, pese a poderse establecer en este sintagma la misma relación proposicional que se da en María se quejó. De hecho, no faltan autores que señalan la contradicción in terminis que supone hablar de oraciones subordinadas, ya que tal término es equivalente al de oraciones que no tienen sentido completo, en donde el modificador relativo aporta unos rasgos que resultan incompatibles con los que definen al sustantivo antecedente. Un ejemplo característico de esta postura lo representa Bello (I988 [i 847]), que considera a las subordinadas proposiciones y reserva la etiqueta de oración para las proposiciones simples o compuestas dotadas de sentido completo.

Por su parte, (f) plantea también un reto al enfoque analítico. Se trata de un enunciado evidentemente bimembre, por lo que si ese es el único criterio que debe emplearse para decidir el estatuto oracional de la secuencia el veredicto debería ser afirmativo. Pero tal opción provocaría una situación contradictoria, ya que, desde el punto de vista de su estructura interna, (f) es idéntica a (c), que se etiqueta como oración subordinada. Por lo tanto, desde la perspectiva analítica, la caracterización de una oración como subordinada no ha de depender de su integración en una oración matriz, sino de ciertos elementos internos que denoten la pertenencia a tal clase, tales como los subordinantes o el modo y la no finitud del verbo. 
Muchos de los autores que aplican el criterio más laxo a la hora de establecer los requisitos para que un enunciado adquiera el rango oracional suelen distinguir a continuación entre el tipo bimembre y el unimembre de oración. Tal es el caso de Bloomfield (I933), que distingue oraciones mayores (sujeto + predicado) y menores (unimembres). Otros gramáticos, en la misma línea, proponen una disociación más clara de las perspectivas holística y analítica reflejadas en el cuadro I, haciendo corresponder a cada plano un concepto sintáctico distinto. De aquí nace la distinción entre sentence y clause en la tradición inglesa o la de phrase y proposition en la francesa. Es importante anotar que tales pares no se corresponden con la distinción entre oración principal y subordinada, ya que tanto unas como otras participan de la consideración analítica de cláusulas o proposiciones. En la tradición española, Andrés Bello (I988 [I 847]: \$308) incorpora esta misma distinción, al definir la oración como proposición o conjunto de proposiciones con sentido completo. Como han estudiado Lope Blanch (I979) y Rojo (1978), la propuesta de Bello no ha llegado a cuajar en nuestra tradición gramatical, de manera que un único término ("oración") suele usarse para traducir tanto la sentence como la clause. De hecho, muchos de los autores que recurren a tal distinción, la usan en un sentido distinto del inicial, para distinguir entre la oración principal ("oración") y la subordinada ("proposición” o "cláusula”). Tal es el caso de Alonso y Henríquez Ureña (I97 I [1935-I936]), Manuel Seco (1974) o Alcina Franch y Blecua (1975), aunque estos últimos solo consideran proposiciones a las subordinadas completivas. El mismo deslizamiento se observa en algunos autores de la tradición francesa, como Martinet (I960).

De este repaso apresurado de la génesis y desarrollo del concepto de 'oración subordinada' se concluye que el término aparece en el siglo XVII, asociado a la emergencia de la sintaxis como disciplina diferenciada del tradicional estudio de las clases de palabras, y que procede del enfoque de la oración que Graffi (200I) califica de analítico, ya que el término oración que contiene remite necesariamente a una estructura bimembre caracterizada por la presencia de marcas internas de subordinación. Más adelante veremos, no obstante, que no resulta fácil mantener este enfoque y que el único modo de convertir en operativo el concepto es añadiendo a esta definición propiedades distribucionales y semánticas propias de la perspectiva que hemos etiquetado como holística. Antes de ello, no obstante, conviene plantearse cuál es la recepción del concepto de 'oración subordinada' en algunas teorías actuales.

\section{El CONCEPto de 'ORACión SUbordinada' en algunas teorías actuales}

Frente al uso habitual del término oración subordinada como etiqueta descriptiva heredada de la tradición, los modelos gramaticales actuales no suelen considerar este concepto como un primitivo teórico, sino que en todo caso lo usan como término 
operativo que engloba un conjunto de construcciones más o menos vinculadas. Como suele suceder con los términos que expresan conceptos derivados, su uso plantea problemas de delimitación, a los que dedicaremos nuestra atención en los siguientes apartados.

Para valorar la presencia del concepto en las teorías contemporáneas, consideraremos cuatro modelos que representan enfoques epistemológicos distintos ${ }^{6}$ :

\begin{tabular}{l|l|l}
\multirow{2}{*}{$\begin{array}{l}\text { MODELOS } \\
\text { FORMALES }\end{array}$} & Basados en las categorias & Gramática generativa \\
\cline { 2 - 3 } & Basados en las dependencias & Funcionalismo de Alarcos \\
\hline \multirow{2}{*}{$\begin{array}{l}\text { MODELOS } \\
\text { FUNCIONALES }\end{array}$} & De base experiencialista & Lingüística cognitiva \\
\cline { 2 - 3 } & Basados en la noción de tipo & Tipología
\end{tabular}

CuAdro 2. Modelos formales y funcionales

El cuadro anterior es sumamente esquemático, ya que ni refleja en toda su complejidad el panorama de modelos activos en la investigación lingüística ni el modelo concreto elegido para cada corriente es el único que podría aducirse. Además, soy consciente del riesgo que contraigo al referirme a modelos que parten de presupuestos diametralmente distintos, pues como acertadamente señala Rojo (200I: 67), "la 'traducción' de conceptos - y términos- entre aproximaciones teóricas distintas constituye un ejercicio siempre incómodo y peligroso”.

\section{I. Los modelos formales}

En general, puede decirse que los modelos formales no toman la noción de subordinación como un primitivo teórico, sino que la derivan de otros mecanismos más básicos. En el caso de la gramática generativa, el giro lexicista que se operó desde la aparición del modelo de principios y parámetros (Chomsky I98I) supuso un cambio importante respecto de la consideración de la oración, que pasó de ser tomada como elemento axiomático (y por lo tanto primitivo) en toda derivación sintáctica a convertirse en el resultado de la proyección de determinados núcleos funcionales de valor temporo-aspectual. Es decir, que de un modelo analítico basado en la segmentación de constituyentes se pasa a un modelo sintético en el que las construcciones

\footnotetext{
${ }^{6}$ Somos conscientes de que la consideración del funcionalismo de Alarcos como modelo formal y no funcional puede resultar chocante. Pese a que las funciones son, efectivamente, nociones primitivas en la gramática de Alarcos —como lo son igualmente en la gramática léxico-funcional (Bresnan 1982) - la prioridad epistemológica otorgada a la forma sobre la función en dicho modelo permiten caracterizarlo como formalista. Sobre las diferencias entre el modelo de Alarcos y otros funcionalismos, $c f$. Rojo I994.
} 
sintácticas se obtienen expansivamente como resultado de la proyección de los núcleos que las encabezan. De este modo, el resultado de una derivación sintáctica admite resultados distintos, en función de cuál haya sido el último núcleo proyectado en la derivación. La oración pasa, por lo tanto, de ser estación de origen obligada a convertirse en uno de los destinos posibles de una representación sintáctica, lo que soluciona la inicial incapacidad del modelo para generar los fragmentos infraoracionales ${ }^{7}$. Este enfoque se ha mantenido y reforzado más si cabe en el modelo minimista, desarrollado a partir de Chomsky I995, en el que hay una única operación computacional capaz de crear estructura: el ensamble o fusión (merge), que hermana a un núcleo con un no-núcleo y forma una entidad composicional compleja. De esta manera, el concepto de 'ensamble' subsume el de 'transformación', que se pasa a interpretar como un caso particular de este:

(I) a. Ensamble externo:

$[\mathrm{N}$ libro $]+[\mathrm{p}$ de $[\mathrm{N}$ filosofía $]]>[\mathrm{N}$ libro [p de [N filosofía $]]$

b. Ensamble interno:

$\left[\mathrm{C} C[\mathrm{~T}\right.$ dices $[\mathrm{N}$ qué $]]>\quad\left[\mathrm{c} \text { quéi } \mathrm{C}\left[\mathrm{T} \text { dices }\left[\mathrm{N} \mathrm{t}_{\mathrm{i}}\right]\right]\right]^{8}$

Es evidente que en el escenario que se acaba de describir el concepto de 'subordinación' tiene un contenido derivativo: será subordinada cualquier construcción oracional que entre en un proceso de ensamble con un núcleo subordinante y que, por lo tanto, quede insertada en una proyección sintáctica más alta. Este enfoque, que resulta en apariencia nítido, plantea diversos problemas que estudiaremos en el próximo apartado. En cualquier caso, el estudio de la subordinación queda centrado en el análisis de las categorías funcionales y léxicas que tienen la capacidad de seleccionar proyecciones oracionales. Es interesante anotar que el camino emprendido por el generativismo a partir de I98 I supone un acercamiento al enfoque que caracterizó el tratamiento de la sintaxis en las gramáticas tradicionales, ya que las construcciones complejas se explican a partir de las propiedades morfosintácticas de ciertas categorías que las proyectan. Por supuesto que el generativismo sigue usando una

\footnotetext{
${ }^{7}$ A no ser, claro está, que se consideren restos fónicos de oraciones a los que se les aplican mecanismos de elipsis, como han argumentado autores como Merchant (200I, 2004). Para un resumen de los distintos enfoques de la elipsis en las teorías formales, $c f$. Merchant $20 \mathrm{I} 8$.

${ }^{8}$ En ( $\mathrm{rb}$ ) las etiquetas T y C representan, respectivamente, las categorías funcionales de "tiempo" y "complementante", que son las que encabezan las oraciones. Nótese que la distinción entre ambas no corresponde a la oposición entre principal y subordinada, pese a lo que a primera vista pudiera parecer, dado que las oraciones interrogativas o exclamativas proyectan $\mathrm{C}$ aun siendo principales. La distinción entre ambas proyecciones funcionales se corresponde más bien con las nociones de 'anclaje temporal' y 'fuerza ilocutiva', respectivamente. En el llamado modelo cartográfico (Cinque y Rizzi 20 Io), el nodo $\mathrm{C}$ queda descompuesto en una serie de proyecciones funcionales que reflejan la estructura informativa de la oración y su valor ilocutivo (como Fuerza, Tópico y Foco, entre otras). Sobre la evolución de la estructura de la oración en el modelo generativo, véase Brucart y Hernanz 20 i 5.
} 
estructura jerárquica de constituyentes, pero ésta se deriva uniformemente de la interacción entre el léxico y ciertos principios computacionales básicos, como el binarismo, la recursividad y la endocentridad ( $c f$. Brucart y Hernanz 20 I 5 ).

En el caso del funcionalismo de Alarcos, la noción de 'oración subordinada' tampoco desempeña un papel propio, ya que se las considera "oraciones degradadas", esto es, transpuestas a una categoría no verbal. De este modo, el mecanismo de la transposición subsume todos los casos de subordinación. En palabras de Gutiérrez Ordóńez (I999: 48), "las oraciones subordinadas ni son oraciones ni son subordinadas".

La primera negación se justifica al observar el análisis que se propone para el conjunto que le dejan solo en la siguiente oración: el transpositor que habilita a la oración para funcionar como nombre (esto es, como suplemento del verbo principal):

(2) (Gutiérrez Ordóñez, I999: 58)

Se queja de $\frac{\left\lfloor\frac{\text { que }}{\text { tr. }} \frac{\lfloor\text { le dejan solo }}{\mathrm{O}} \mid\right.}{\mathrm{N}}$

A la vista de (2) queda claro que la secuencia que le dejan solo no se considera como una oración, sino como un nombre obtenido mediante el procedimiento sintáctico de la transposición.

La segunda se cimienta en el supuesto de que la noción de 'subordinación' pertenece al plano de las funciones y no al de las categorías. Así pues, el funcionalismo alarquiano rechaza el término de oración subordinada no porque considere que tales unidades del análisis tradicional no constituyan secuencias en el análisis de las construcciones que las presentan, sino porque considera que tal etiqueta no refleja adecuadamente ni su categoría ni su función. De hecho, puede establecerse una regla de correspondencia entre ambos términos: lo que la tradición gramatical ha denominado oración subordinada corresponde en el modelo funcionalista que estamos analizando a una oración precedida de un transpositor. La propia noción de 'oración degradada', término usado por Alarcos (1994), parece avalar esta idea. Nótese, por otra parte, que la distinción entre el formante interno oracional y la proyección que incorpora el subordinante es paralela a la que se establece en la gramática generativa entre la oración propiamente dicha, que se etiqueta como proyección de la categoría funcional Tiempo, y la subordinada, que se identifica como proyección del complementador o 
elemento subordinante. La diferencia, por lo tanto, se limita al concepto de 'endocentricidad', que la gramática generativa aplica a todas las proyecciones, mientras que el proceso de transposición encaja más bien con la noción de 'exocentricidad'.

\subsection{Los modelos funcionales de base semántico-pragmática}

Pese a la considerable distancia conceptual que existe entre los dos modelos formales que acabamos de examinar, se observa que ambos sitúan, en el mejor de los casos, el término de oración subordinada en el terreno de los conceptos derivados. En cambio, en los modelos funcionalistas de base semántico-pragmática la noción de 'subordinación' ocupa en ocasiones un papel relevante. Nótese que decimos subordinación y no oración subordinada porque estos modelos no suelen manejar primitivos categoriales. En el modelo cognitivo de Langacker (I987-I99I, vol. 2: 436), por ejemplo, una oración subordinada es aquella cuyo perfil queda neutralizado o desplazado (overriden) por el de la oración principal. Así, mientras que en Se ha ido lo que se perfila es un proceso que expresa movimiento desde un origen, en Dice que se ha ido se superpone al anterior el perfil de un proceso de transmisión de información. Esto diferencia la subordinación de la coordinación, donde ninguno de los perfiles correspondientes a los miembros se impone sobre el resto. Por lo tanto, la característica de las oraciones subordinadas es que carecen de perfil independiente.

El último modelo que mencionaremos es el que se presenta en Cristofaro 2003 con el objetivo de obtener generalizaciones sobre las construcciones subordinadas en lenguas de tipologías distintas. Se trata de un modelo tipológico basado en las escalas de universales implicativos. Para la autora, el concepto básico que corresponde a la subordinación es la 'falta de asertividad pragmática', que deriva de la disposición asimétrica que caracteriza a los estados de cosas relacionados por medio de la subordinación. Una prueba capaz de detectar el núcleo asertivo en las subordinadas es la negación oracional. El estado de cosas afectado por ésta es el elemento asertado en la oración afirmativa correspondiente, tal como se muestra en (3):

(3) a. Luis llegó y María se fue (COORDINACIÓN)

a'. No es verdad que Luis llegara y María se fuera (se niega la veracidad de los dos estados de cosas o la de uno cualquiera de ellos)

b. María se fue cuando Luis llegó (SUBORDINACIÓN)

b'. No es verdad que María se fuera cuando Luis llegó (no se niega la veracidad del estado de cosas descrito por la subordinada)

Cristofaro (2003: 38-39) define del siguiente modo las tres clases tradicionales de subordinación: 


\begin{tabular}{c|l} 
Completiva & $\begin{array}{l}\text { La semántica de uno de los estados de cosas entraña la remisión a } \\
\text { otro estado de cosas. }\end{array}$ \\
\hline AdVERBial & $\begin{array}{l}\text { Uno de los estados de cosas vinculados corresponde a las circuns- } \\
\text { tancias bajo las cuales el otro tiene lugar. }\end{array}$ \\
\hline ReLATIVA & $\begin{array}{l}\text { Un participante en el estado de cosas principal se identifica en un } \\
\text { conjunto de referentes posibles por medio de la mención de otro } \\
\text { estado de cosas en el que aquél a su vez participa. }\end{array}$ \\
CUADRO 3. Las tres clases de subordinación en Cristofaro 2003
\end{tabular}

Es interesante anotar que las anteriores definiciones, que atienden a lo que hemos denominado perspectiva holística, están basadas exclusivamente en el contenido y no en la forma, de modo que una oración como Luis se fue tras la llegada de María cumpliría en principio las condiciones establecidas para la subordinación completiva, pese a no contener más que un verbo. No obstante, esto no provoca problemas en los modelos tipológicos, ya que la comparación interlingüística muestra lenguas en las que la diferencia entre la subordinación oracional y otras construcciones eventivas de carácter nominal son mucho más tenues que en las indoeuropeas.

\section{LAS FRONTERAS ENTRE PRINCIPALES Y SUBORDINADAS}

\section{I. Las propiedades formales de las subordinadas}

En los dos apartados que restan de este trabajo estudiaremos algunos problemas de límites que plantean las subordinadas. En este nos centraremos en los límites externos, que delimitan el contraste entre principal y subordinada, y el siguiente lo dedicaremos a estudiar los límites internos entre las distintas clases de subordinadas.

Como se ha señalado, en la tradición formal el concepto de 'oración subordinada' procede del enfoque analítico del estudio de la oración. De ahí que la caracterización de las subordinadas se centre en determinar cuáles son sus propiedades distintivas internas frente a las principales. Entre tales características formales internas que pueden servir como indicio de subordinación se han mencionado las siguientes?:

\footnotetext{
${ }^{9}$ Como acertadamente señala uno de los revisores, la lista del cuadro 4 reúne características muy diversas. Mientras que (a) es condición suficiente para la subordinación, (b) no lo es, dada la existencia de formas verbales no personales en las perífrasis aspectuales y modales. Por otra parte, (a) y (b) son incompatibles, pero una de ellas es condición necesaria para la existencia de subordinación.
} 

a. La presencia de nexos de subordinación
b. Las formas no personales del verbo
c. El modo subjuntivo
d. La posibilidad de establecer dependencias a larga distancia
e. La pronominalización catafórica
f. El orden de palabras

CUADRO 4. Indicios formales de subordinación

Pese a que la lista de propiedades del cuadro 4 es nutrida, no siempre resulta posible establecer claramente la frontera entre subordinadas y principales apelando a tales características. De ahí que haya que recurrir con frecuencia a criterios externos (es decir, a la perspectiva holística):

a. Inclusión en una proyección léxica superior

b. Falta de fuerza ilocutiva independiente

Cuadro 5. Características externas de la subordinación

A continuación, presentaremos algunos casos en los que la frontera entre oración principal y subordinada resulta difusa si se aplican únicamente los criterios internos. Tómese el contraste de (4):

(4) a. Te deseo que lo consigas.

b. Que lo consigas.

La subordinada de (4a) aparece literalmente reproducida en (4b) como enunciado independiente con modalidad desiderativa. De hecho, las gramáticas suelen referir estos casos como ejemplo del llamado subjuntivo independiente. No obstante, la presencia en el encabezamiento de la oración de la misma conjunción subordinante que en (4a) sugiere que ambas secuencias son idénticas desde el punto de vista de su arquitectura gramatical. Se plantea, pues, la cuestión de si (4b) debe considerarse principal o subordinada. Un modo de regularizar la situación consiste en suponer que en (4b) se ha elidido el mismo predicado principal que aparece en (4a). Si se acepta esta opción de análisis, el problema queda resuelto: (4b) contiene una oración subordinada completiva regida por un verbo desiderativo implícito. Pero la catálisis de tal predicado implícito no siempre es tan evidente como en este caso. Así, en los ejemplos de (5), obtenidos del CREA, la introducción del supuesto predicado elíptico daría como resultado una secuencia poco natural:

(5) a. Siempre me confesé de lo mejor. Que te lo diga el padre Alfonso. Él lo sabe todo de mí. (Ángel Vázquez, La vida perra de Juanita Narboni) 
b. Que te baste saber que la motivación que me parece más probable es de carácter... amoroso. (Fernando Savater, Caronte aguarda)

Otra opción es considerar que la conjunción que encabeza (4b) no es la misma que la que vincula la subordinada a la principal en (4a): mientras que en este último caso se trataría de una conjunción subordinante completiva, en (4b) sería una conjunción modal. En este análisis, el elemento que desencadena el subjuntivo en la subordinada en (4a) es el verbo desear, mientras que en (4b) sería la conjunción la responsable de la selección de tal modo. Esta opción presenta ventajas sobre la anterior, pero no resuelve por sí misma la cuestión de si (4b) debe considerarse subordinada o no. Por una parte, la presencia de una conjunción al frente de la oración llevaría a suponer que se trata de una subordinada, pero no existiría un predicado selector que la seleccionara, ya que el estatuto que como máximo podría atribuirse al que de (4b) es el de operador de modalidad. De hecho, si la decisión en este caso es considerar subordinada a la oración, debería otorgarse la misma consideración a oraciones como Ojalá lo consigas o Tal vez lo consigas, ya que ambas aparecen encabezadas por operadores de modalidad no aseverativa.

Ante la dificultad de determinar el carácter principal o subordinado de (4b) en función únicamente de las características formales internas de tal construcción, se suele recurrir a los factores externos, que son de índole sintáctica y semántica, y que tienen en cuenta criterios discursivos. Si se aplican los dos criterios señalados en el cuadro 5, la conclusión que se obtiene es que (4b) no debe considerarse una oración subordinada, puesto que ni aparece incluida en ninguna proyección léxica más amplia ni carece de fuerza ilocutiva, ya que por sí misma constituye un acto de habla consistente en la expresión de un deseo. La incorporación de los factores externos a la hora de determinar si una oración es principal o subordinada tiene como consecuencia hacer depender la decisión en algunos casos de condiciones contextuales. Así, si la misma secuencia de (4b) apareciera en un contexto dialógico como el de (6), el resultado respecto de las pruebas externas sería el contrario, ya que el mismo enunciado carece de fuerza ilocutiva propia:

(6) - ¿Qué dices que no te crees?

-Que lo consigas.

En la gramática generativa, la diferencia entre los dos ejemplos estudiados no vendría dada por la categoría a la que pertenecen — ya que en ambos casos se conciben como proyección de los respectivos complementadores-, sino porque su valor semántico es radicalmente distinto: predicación en $(4 \mathrm{~b})$ y argumento proposicional en (6). 
Otro caso que plantea un problema idéntico al que acabamos de estudiar es el que se da entre las interrogativas parciales y las interrogativas indirectas:

(7) a. Me gustaría saber cuándo vendrás.

b. Ya sé cuándo vendrás.

c. ¿Cuándo vendrás?

De nuevo hay que dar entrada a los criterios externos de evaluación a la hora de decidir la naturaleza principal o subordinada de estas oraciones interrogativas. Se podría argumentar que la noción de independencia prosódica es un factor interno capaz de establecer la diferencia en estos ejemplos, pero más bien parece que tal característica está directamente relacionada con la estructura sintáctica y deriva del hecho de que una oración esté incluida o no en otra proyección léxica. Recuérdese, por otra parte, que un mismo enunciado como Que lo consigas podía ser etiquetado como oración principal o subordinada en función del contexto, a pesar de que resulta evidente que su manifestación prosódica en ambos casos es básicamente la misma.

\subsection{El modo y las formas no finitas}

Por lo que se refiere al resto de características internas de las subordinadas, ya hemos comprobado que el modo subjuntivo no es una marca segura de subordinación oracional. De hecho, de la argumentación precedente se deriva que Que te vayas, con el verbo en subjuntivo, puede ser una oración principal, frente a Que te vas, que solo puede considerarse un fragmento oracional (formado, por lo tanto, por una oración subordinada). En cuanto a las formas no personales del verbo, es cierto que suelen aparecer en contextos de subordinación, pero también pueden encabezar actos de habla como en los siguientes ejemplos, tomados del CREA:

(8) a. [...] tenemos ya poco tiempo. Tan solo decirles que el Rayo Vallecano viaja en estos momentos por carretera también hacia Sestao. (Radio Madrid, 8/I2/I99I)

b. ¿Ir allí la policía? No, hombre, ahí nada más que iban los comerciantes a comprar para revender. (Miguel Barnet, Gallego)

c. ¡Negarme esa plaza a mí, con mi Premio Extraordinario! (José Luis Sampedro, La sonrisa etrusca)

d. '¿Qué hay, Mateu?', le dijo mi padre con calma. ‘¿Viendo mejor el cuadro?'. (Javier Marías, Corazón tan blanco)

La conclusión que se obtiene de los ejemplos estudiados hasta aquí es que resulta difícil dar una caracterización global de los factores internos que singularizan a una oración subordinada, ya que los más evidentes aparecen, más o menos esporádicamente, en oraciones que no pueden ser calificadas de tales. 


\subsection{Las subordinadas discontinuas}

Como hemos indicado en el cuadro 4, una de las propiedades asociadas con ciertas clases de oraciones subordinadas es la posibilidad de presentar dependencias a distancia, como en (9):

(9) a. ¿Qué crees que sucederá?

b. ¿Qué hermosa dicen que es Manila!

c. Todavía estoy buscando el libro que dijiste que habías colocado en el secreter.

Las dependencias a distancia consisten en que un elemento de la subordinada aparece desplazado en alguna oración superior. Así, por ejemplo, el elemento en cursiva es en (9a) el sujeto de suceder, en (9b) el atributo de la oración copulativa y en (9c) el complemento directo de colocar. Solo las oraciones subordinadas completivas que funcionan como complemento de un verbo admiten este tipo de dependencia. Así, por ejemplo, en (9c) el elemento que encabeza la subordinada es un pronombre relativo, pero su ascenso desde la oración de colocar a la de decir ha sido posible porque la primera es subordinada completiva de la segunda. No nos interesa aquí entrar en el detalle de las restricciones que rigen estas construcciones. Nos limitaremos a plantear la pregunta de dónde empieza y dónde acaba la subordinada en estos casos. Por una parte, es obvio que los elementos destacados son componentes de oraciones subordinadas en las que desempeñan una función gramatical: complemento directo en (9a) y (9c), y atributo en (9b). Pero también lo son de las oraciones superordinadas que encabezan, ya que en ellas ejercen simultáneamente una segunda función: la de operadores de polaridad interrogativa y exclamativa en (9a) y (9b), respectivamente, y la de nexo subordinante relativo en (9c). Se trata, por lo tanto, de elementos bifuncionales, que a su naturaleza de argumentos del predicado de la subordinada acumulan una función característica de ciertas proyecciones funcionales. En la gramática generativa, la doble dependencia de estos elementos se representa suponiendo que en el primer nivel de la derivación se generan en el interior de la subordinada y que luego sufren un proceso transformacional de elevación a la periferia izquierda de la oración en la que aparecen fonéticamente representados. En la versión de principios y parámetros la posición en el interior de la subordinada se representaba por medio de una huella, pero en el modelo minimista se opta por sustituir las huellas por copias de la entidad desplazada. Una regla del componente fonético determina que la única instancia con realización fonética es la que ocupa la posición más elevada en la representación sintáctica:

(Iо) ¿Qué crees [c qué que [T qué sucederá qué? ]]] 
En (Io) las tres copias sin realización fonética se proponen por motivos independientes. La que aparece a la derecha del verbo suceder indica que el pronombre interrogativo es el argumento interno de ese verbo inacusativo (el papel temático correspondiente a este argumento, por lo tanto, es el de $<$ TEMA $>$ ). La siguiente copia a la izquierda indica que la función gramatical que desempeña el interrogativo en la subordinada es la de sujeto. Finalmente, la tercera copia no expresa se propone por razones internas de la teoría, ya que se supone que las transformaciones de movimiento están sometidas a un principio de ciclicidad que impone que el elemento interrogativo pase por la periferia izquierda de la oración en la que se ha generado antes de proyectarse en la misma posición de la oración matriz.

\section{LOS LÍMITES ENTRE LAS SUBORDINADAS}

\section{I. Las tres clases tradicionales de subordinadas y algunas propuestas de ampliación}

Bajo la etiqueta de subordinadas se incluyen construcciones que presentan diferencias sustanciales. De ahí que se hayan organizado en distintas subclases. Graffi (200 I: I I6) atribuye al gramático alemán Simon Herling la propuesta que sin duda ha tenido más éxito de todas y que consiste en agruparlas según la relación que establecen con otras categorías léxicas, teniendo en cuenta la función que aquellas desempeñan respecto del elemento al que complementan o modifican: sustantivas, adjetivas o adverbiales (Herling I 82 I). No podemos estudiar todos los problemas e inconsistencias que se derivan de esta clasificación, porque tal empresa daría sobradamente para más de una monografía. En un cómputo apresurado efectuado sobre las dos gramáticas más detalladas del español con que contamos (Bosque y Demonte I 999, RAE y ASALE 2009), se observa la importancia que se le otorga a los fenómenos de subordinación. Por lo que respecta a la primera obra, a la subordinación sustantiva se le dedican siete capítulos, que ocupan 487 páginas; la subordinación adverbial se trata en seis capítulos (cuatro enteros y dos mitades de capítulo), con 368 páginas, y la subordinación relativa se aborda en dos capítulos y medio, que abarcan 223 páginas. En total, I078 páginas, que representan el 21,17\% del total de la obra. El cómputo en la nueva gramática académica arroja cifras similares: 202 páginas para la subordinación completiva, I 32 para la relativa y 334 para la adverbial, lo que suma 668 páginas, un i $8 \%$ del total de la obra ${ }^{10}$.

\footnotetext{
${ }^{10}$ Debe tomarse este cálculo como aproximado, sobre todo en lo referido a la Nueva gramática... En efecto: en este caso se han tenido en cuenta solamente los capítulos específicamente dedicados a las construcciones subordinadas, sin
} 
De las tres subclases de subordinadas, es sin duda la de las adverbiales la que plantea mayores problemas de delimitación ${ }^{11}$. De hecho, algunos autores que han abordado su estudio, como Narbona (I989-I990) y Rojo (I978) se han mostrado partidarios de dividir ese grupo en dos clases independientes: una (la de las adverbiales propiamente dichas) abarcaría construcciones como las locativas, temporales, modales, que representan funciones que pueden expresarse por medio de complementos circunstanciales representados por un adverbio; la otra (la de las adverbiales impropias) reuniría el resto de subordinadas tradicionalmente etiquetadas como adverbiales. El propio Rojo (1978) propone considerar bipolares a una subclase de las adverbiales impropias y a las adversativas, tradicionalmente clasificadas entre las coordinadas. La particularidad semántica de las adverbiales impropias, como señala Rodríguez Ramalle (2005: 573), es que principal y subordinada mantienen una relación de implicación mutua entre los eventos representados por una y otra. Esta diferencia tiene una traducción frecuente en la gramática pedagógica. Si le pedimos a un estudiante que nos dé un ejemplo de subordinada temporal, lo más probable es que no incluya en la respuesta la principal. Por lo tanto, cuando Luis se fue sería una posible respuesta correcta. En cambio, si se le solicita una oración condicional, es bastante improbable que solo aporte la prótasis encabezada por el correspondiente nexo (si llueve). Lo más habitual en este caso es que se aduzca la construcción entera (Si llueve, no iremos). Este hecho queda reflejado con frecuencia en las gramáticas tradicionales, en las que se habla del período condicional para incluir tanto la prótasis como la apódosis.

De cualquier modo, Rodríguez Ramalle (2005) defiende el carácter de subordinadas adverbiales de estas construcciones basándose en el hecho de que la relación implicativa solo se da cuando la subordinada modifica la predicación. Para los casos en que la modificación se efectúa en el nivel de la modalidad y actúa sobre la enunciación (Si tienes hambre, hay queso en la nevera, en donde es evidente que la existencia de queso en la nevera no depende de que tengas hambre), Gutiérrez Ordóñez ( I999) propone mecanismos de recuperación del material enunciativo implícito para restablecer la relación condicionante-condicionado ${ }^{12}$.

La controversia respecto a la subordinación adverbial está, por otra parte, relacionada con un problema más general que atañe a todos los adjuntos. A diferencia de

\footnotetext{
incluir los epígrafes a ellas referidos en el capítulo de presentación ni las menciones que a ellas se hacen en otros capítulos de la obra.

${ }^{11}$ Sobre lo inadecuado de la denominación de estas subordinadas, cf. Bosque y Gutiérrez-Rexach 2009: 732-733. Estos autores proponen asimismo análisis alternativos para varias subclases de las adverbiales tradicionales (Bosque y Gutiérrez-Rexach 2009: 733-739). Sobre las estructuras sintácticas involucradas en la subordinación adverbial, véase Pavón Lucero 20I2.

${ }^{12}$ Véanse a este respecto Brucart y Gallego 2009 y 20I6, donde se propone una reformulación del enfoque formal de las subordinadas adverbiales y se trata la distinción entre subordinadas del enunciado y subordinadas de la enunciación como una consecuencia del distinto nivel jerárquico de subordinación de una y otra clase.
} 
los argumentos, cuya presencia viene impuesta por requisitos de selección léxica, la opcionalidad de los adjuntos se ha justificado semánticamente por el hecho de que son meros modificadores del predicado. Pero algunas teorías semánticas más modernas otorgan a esta clase de elementos mayor relevancia. En concreto, en la semántica neodavidsoniana (Parsons I990), los adjuntos son predicados del evento. Esa es, por ejemplo, la opción que adopta el diccionario combinatorio Redes (Bosque 2004), que tiene como objetivo básico informar de las clases de eventos seleccionados por los predicados, entendiendo como tales no solo los verbos, sino también los adjetivos o los adverbios. Desde la perspectiva neodavidsoniana, resulta natural que cuando el adjunto tiene valor eventivo, del resultado de su predicación sobre otro evento se obtengan relaciones implicativas entre eventos, como las que caracterizan a las llamadas subordinadas impropias. Esto es, en cambio, mucho más difícil de conseguir si se supone que los adjuntos son miembros modificadores de la oración principal, ya que en tal caso la interpretación semántica que se deriva es la de inclusión del evento subordinado en el que expresa la principal.

\subsection{Algunas propuestas de reducción}

En sentido opuesto a las propuestas de aumentar las tres clases tradicionales de subordinadas adverbiales, también se detectan en la bibliografía algunas otras de naturaleza reduccionista. Mencionaremos brevemente dos de ellas.

La primera tiene que ver con el establecimiento de las fronteras de las subordinadas adverbiales. Una buena parte de ellas aparecen introducidas por lo que la gramática tradicional ha considerado locuciones conjuntivas, como para que o a fin de que. En (I I) se observa que muchas de tales unidades, sin la presencia del que conjuntivo, pueden regir igualmente sintagmas nominales o infinitivos:

(I I) a. Lo hice para él.

b. Lo hice para recompensarlo.

c. Lo hice para que se sintiera bien.

Para las teorías que conciben la preposición como un núcleo capaz de regir oraciones subordinas, como la gramática generativa, la opción más económica de análisis para (I I) es la que se esquematiza en (I 2), donde SC representa la proyección correspondiente a una oración subordinada (téngase en cuenta que en este modelo gramatical los infinitivos forman oraciones):

(I2) a. Lo hice [sp para [sN él]].

b. Lo hice [sp para [sc recompensarlo]].

c. Lo hice [sp para [sc que se sintiera bien] $]^{13}$. 
El análisis de (I 2) trata de modo idéntico todas las instancias de la preposición para y, en el caso de (I2c), considera que la oración subordinada no es para que se sintiera bien, sino que se sintiera bien, que es una subordinada completiva o sustantiva. Este análisis ha sido adoptado, por ejemplo, en una de las gramáticas de referencia del inglés más recientes (Huddleston y Pullum 2002). Estos autores reducen las subordinadas a las relativas, comparativas y contentivas (content clauses) ${ }^{14}$. El último grupo equivale a las completivas. La ausencia de las tradicionales cláusulas adverbiales se explica así:

A high proportion of traditional adverb (or adverbial) clauses are on our analysis PPs consisting of a preposition as a head and a content clause as complement: before you mentioned

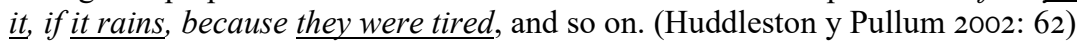

La segunda propuesta reduccionista afecta a las adverbiales llamadas propias (temporales, locativas y modales). Para buena parte de la tradición gramatical española (y señaladamente para Bello), estas oraciones están encabezadas por adverbios relativos sin antecedente explícito (donde, cuando, como, mientras... $)^{15}$. De hecho, Narbona (1989-1990, vol. I: 33) les asigna la etiqueta híbrida de "relativo-adverbiales”. Así, pues, según este análisis, las llamadas adverbiales propias serían estructuras relativas.

\subsection{Los limites entre las relativas y las completivas}

Como se deduce de lo dicho en los anteriores apartados, el estatuto más inestable dentro de las subordinadas corresponde a las adverbiales, tanto por las diferencias que presentan entre sus distintas subclases como por la posibilidad de asignarles análisis alternativos que las incorporen a las otras clases de subordinadas. En cambio, la

\footnotetext{
${ }_{13}$ Podría argüirse que un análisis como el de (I2) no es trasladable al caso de a fin de que, dado que este nexo complejo no admite complementos que no sean oracionales ( ${ }^{*}$ a fin de ello) y, por otra parte, el sustantivo, al ir desprovisto de cualquier tipo de determinante, muestra claros signos de fijación locucional. Pero, independientemente de que a la locución preposicional a fin de se le otorgue o no un análisis interno, no parece necesario suponer que existe paralelamente una locución conjuntiva a fin de que. Resulta más económico suponer que esta última secuencia se obtiene composicionalmente por el ensamble de la locución preposicional y una subordinada completiva, lo que permite asignar una estructura idéntica cuando esta última es una oración de infinitivo: a fin de recompensarlo.

${ }^{14}$ La desaparición de las adverbiales como una de las clases de subordinadas se atestigua también en la más célebre gramática del francés: Le bon usage, de Grevisse. A partir de la I 3. a edición de esta obra clásica (Grevisse I993 [I936]) se distinguen únicamente dos clases de oraciones subordinadas: las propositions rélatives y las propositions conjonctives. La clasificación, por lo tanto, atiende exclusivamente al tipo de nexo subordinante.

${ }^{15}$ La nueva gramática académica (RAE y ASALE 2009) adopta este análisis para dichas construcciones y, de modo coherente, la $23 .^{\mathrm{a}}$ edición del diccionario (RAE y ASALE 20I4) caracteriza la principal acepción de estos nexos como adverbios relativos. No obstante, en otros valores secundarios se consideran conjunciones (por ejemplo, en los valores condicionales o concesivos de cuando) o preposiciones (cuando la guerra). Es evidente que lo ideal sería asignar una sola categoría a estos nexos y derivar las diferencias de otros factores, pero esa es una empresa que no podemos abordar aquí. Véanse al respecto algunas propuestas en Brucart y Gallego 2009 y 2016 . Sobre los cambios en las fronteras entre relativos, interrogativos y conjunciones desde una perspectiva histórica, $c f$. Espinosa Elorza 2016.
} 
frontera que separa las subordinadas completivas y las relativas parece mucho mejor establecida. No obstante, también se dan fenómenos de frontera difusa entre ambas clases. El caso más evidente de ello es el que afecta a las denominadas construcciones de artículo definido y cláusula relativa con valor enfático. La subordinada que aparece en estas oraciones, sobre las que existe bastante bibliografía (Plann I982 y I984, Bosque 1984, Brucart 1993, Gutiérrez-Rexach 1999), se ha considerado tradicionalmente una relativa. Los contextos en que aparecen estas construcciones son los siguientes:

\begin{tabular}{l|l}
$\begin{array}{l}\text { En enunciados exclamati- } \\
\text { vos independientes }\end{array}$ & $\begin{array}{l}\text { iLas tonterías que dice este necio! } \\
\text { iLo contento que se puso aquel día! } \\
\text { iEn el lío que nos ha metido! }\end{array}$ \\
\hline $\begin{array}{l}\text { Con un predicado que se- } \\
\text { lecciona interrogativas indi- } \\
\text { rectas }\end{array}$ & $\begin{array}{l}\text { No quiero ni imaginar el dinero que le habrá costado } \\
\text { todo esto. } \\
\text { No recuerdo lo que me pidió. }\end{array}$ \\
\hline $\begin{array}{l}\text { Con un predicado que se- } \\
\text { lecciona exclamativas indi- } \\
\text { rectas }\end{array}$ & $\begin{array}{l}\text { Mira lo bien que escribe. } \\
\text { Es increible las tonterias que llega a decir. }\end{array}$
\end{tabular}

Cuadro 6. Contextos de aparición de las construcciones de artículo definido y cláusula relativa con valor enfático

Por otra parte, todas estas construcciones pueden conmutarse por interrogativas indirectas o exclamativas directas o indirectas: ;Qué tonterías dice...!', ;Qué contento se puso...!, No quiero imaginar cuánto dinero le habrá costado; No recuerdo qué me pidió; Mira qué bien escribe; Es increible qué tonterías dice.

Atendiendo a la clase de predicados que las seleccionan y a la relación de paráfrasis que se observa al conmutar estas construcciones por interrogativas y exclamativas indirectas, se ha propuesto analizar estas oraciones como completivas con ascenso del elemento enfático a la izquierda del subordinante completivo que. En (I 3 ) se representan los dos estadios sucesivos de la derivación:

(I3) a. No sabes [Cp que dice las $[+\mathrm{E}]$ tonterías]

b. No sabes [cP las tonterías que dice

De este modo, el sintagma enfático las tonterías se traslada al frente de la subordinada del mismo modo que lo hacen los elementos exclamativos e interrogativos en las correspondientes construcciones indirectas. El análisis que trata estas construcciones como interrogativas o exclamativas indirectas posee la ventaja sobre el análisis relativo tradicional de reflejar adecuadamente la selección por parte del predicado, 
de explicar los casos de silepsis del sujeto (como en Es una vergüenza las cosas que dice), la pronominalización por lo en casos como No sé las cartas que le he enviado ( No lo/*las sé) y la inversión obligatoria del sujeto (;Las cosas que dice este hombre! frente a ${ }^{*}$ iLas cosas que este hombre dice.).

Pese a sus innegables ventajas, el análisis aquí esbozado choca con un problema cuando se aplica a las construcciones encabezadas por el artículo neutro. Se trata de casos como (I4):

(I4) a. Me sorprendió lo calladas que estuvieron las niñas.

b. Es increíble lo duros que están estos filetes.

El aspecto que llama la atención en estas oraciones es la falta de concordancia entre el artículo neutro y el adjetivo que lo acompaña. Nótese que en todos los demás casos en los que aparece la forma neutra del artículo junto a un adjetivo, se establece concordancia en masculino singular (lo duro de la reunión frente a lo dura que fue la reunión). En el análisis de ascenso del artículo enfático, las representaciones subyacentes de las oraciones de (I4) serían las que se reflejan en (I 5):

(I 5) a. Me sorprendió [CP que las niñas estuvieron $l_{[+\mathrm{E}]}$ calladas]

b. Es increíble [ Сг que estos filetes están $l o_{[+\mathrm{E}]}$ duros]

Es decir, que según este análisis es necesario generar en la EP los sintagmas lo calladas y lo duros, lo que representa un problema serio para la teoría de la concordancia del artículo neutro. Gutiérrez-Rexach (1999) propone un análisis alternativo que evita este problema. Para este autor, el artículo neutro es el elemento seleccionado por el predicado, y el único elemento que asciende a una posición focal a la izquierda de la subordinada es el adjetivo. El artículo neutro admite la selección de esta clase de predicados porque denota un grado:

(I6) a. Me sorprendió $\mathrm{lo}_{[+\mathrm{E}]}$ [CP que las niñas estuvieron calladas]

b. Es increíble $\mathrm{lo}_{[+\mathrm{E}]}[\mathrm{CP}$ que estos filetes están duros]

Una importante ventaja de este análisis es que permite explicar la concordancia que manifiesta el atributo en estos casos: la que corresponde al sujeto de la oración atributiva. Por lo tanto, cuando esa unidad ascienda a la izquierda de la subordinada, ya habrá adoptado sus rasgos flexivos, lo que explica la diferencia con el artículo neutro. Una prueba a favor de este análisis la provee la existencia en español de construcciones que reproducen el orden de (I6) hasta el siglo XVII. Los datos de (I7) están tomados del CORDE:

(I7) a. [...] es parecido a la naturaleza mudable y bulliciosa de las mujeres, y en lo que son importantes y necesarias. (Lope de Vega, La Dorotea, I632) 
b. [...] recátanse, que lo que son prontos al censurar son recatados al hablarlo. (Baltasar Gracián, El Discreto, I646)

c. [...] por esta expiriencia se podrá saber el altura del polo y lo que están apartadas d'él todas las otras estrellas. (Martín Cortés Albacar, Breve compendio de la esfera y de la arte de navegar, I 55 I)

Un último argumento a favor de esta segunda opción de análisis lo proporciona el contraste de (I8):

(i8) a. Me llama la atención lo escarpado de esos riscos.

b. Me llama la atención lo escarpados que son esos riscos.

Estas oraciones mantienen relación de paráfrasis y, sin embargo, la forma que adopta el adjetivo es distinta, algo que se deduce directamente del análisis propuesto: en (I8a) no hay subordinada y, por lo tanto, el adjetivo debe concordar con el artículo neutro.

La conclusión que se obtiene de estos datos es que la relación entre completivas y relativas puede llegar a ser bastante íntima y que la transición entre ambas clases es menos abrupta de lo que tradicionalmente se había considerado. De hecho, las estructuras de (I6) comparten características de ambas clases de construcciones: en ellas se da el ascenso de un elemento focal, como sucede en las interrogativas y exclamativas indirectas, pero a la vez la estructura básica es la de una relativa de grado.

\section{Epílogo}

En este trabajo se ha intentado argumentar que el concepto de 'oración subordinada' no es un primitivo de las teorías formales porque tiene perfiles difusos y porque su definición responde a criterios híbridos. Se trata, pues, de un término descriptivo que ha sido útil en la tradición para englobar un conjunto de construcciones que presentan entre sí múltiples diferencias.

Por una parte, la clasificación tradicional alude a la función desempeñada por la subordinada respecto del elemento de la oración matriz al que complementa o modifica. Pero esas mismas dependencias las establecen los sintagmas no oracionales, por lo que la subordinación se reduce a los conceptos de complementación o de adjunción, como se señalaba acertadamente en RAE I928: 322:

La dependencia que acabamos de ver en estas oraciones [se refiere a las subordinadas] es de la misma índole que la que hemos estudiado en la Sintaxis de la oración simple, al tratar de los complementos del verbo. La diferencia existe solamente en la naturaleza de los elementos que entran en relación, los cuales en la oración simple son ideas que vienen expresadas por palabras, y en la oración compuesta son juicios que vienen expresados por oraciones. 
Nótese, en efecto, la diferencia con respecto a la denominación de la otra operación sintáctica que puede afectar a las oraciones (la coordinación). En este caso la designación que recibe la coordinación de oraciones no es distinta a la que atañe a la coordinación de otros tipos de sintagma. Es posible que el uso de una terminología propia para las oraciones subordinadas proceda del interés por diferenciarlas de las principales, sobre todo si se tiene en cuenta que una buena parte de la tradición consideraba que la relación que se daba entre ambas no era de inclusión, sino de unión en un mismo plano. A ello se refieren la RAE y la ASALE (2009: 3224) a propósito de la oración Los argentinos deseaban que se mantuviera la convertibilidad:

A diferencia de lo que sostenían algunos gramáticos de la tradición, la oración principal no es los argentinos deseaban, es decir, lo que queda de la secuencia completa al retirar de ella la subordinada. La secuencia los argentinos deseaban no es un segmento sintáctico. Así pues, las oraciones subordinadas se INCRUSTAN o INSERTAN (lat. tardío subordinare 'colocar debajo') en segmentos más amplios que las contienen.

De hecho, si volvemos al texto de RAE 1928 mencionado anteriormente, observamos que el acierto indudable al señalar la naturaleza no diferencial de la subordinación respecto de otros tipos de complementos se ve en parte empańado por la idea de que en la oración compuesta se ponen en relación juicios, mientras que en la simple se articulan ideas. Tal caracterización encaja mal con lo dicho anteriormente, puesto que el juicio o proposición expresado por la principal incluye el de la subordinada.

Por otra parte, el análisis de las propiedades internas de las subordinadas permite observar que las operaciones sintácticas que las generan no son exclusivas de esa clase de construcciones, sino que reproducen las dos operaciones que se dan igualmente en el resto de proyecciones: el ensamble interno y el externo. Esta última operación caracteriza todos los procesos de selección entre un núcleo y su complemento. Así, la conjunción completiva que selecciona oraciones con el verbo en forma personal y, a su vez, es seleccionada por los predicados que toman argumentos proposicionales. Por su parte, el ensamble interno crea dependencias a distancia a través de operaciones de copia y es característico de las unidades que se vinculan simultáneamente a varias posiciones sintácticas. La íntima relación de origen existente entre los pronombres y adverbios relativos, los interrogativos y los exclamativos pone de manifiesto que esta operación tampoco es exclusiva de la subordinación, ya que la misma clase de ensamble que da lugar a una subordinada relativa puede crear una interrogativa indirecta o una oración matriz de esa misma naturaleza con valor ilocutivo de pregunta: 
(19) a. Me molestó la manera [ como lo dijo cømø ]

b. Me molestó [ cómo lo dijo é́m ]

c. ¿Cómo lo dijo cómo?

Así pues, desde el punto de vista formal, el estudio de la subordinación es básicamente el de los nexos subordinantes y las dependencias que estos crean. Eso encaja mal con la tendencia a seguir un criterio de clasificación basado en las afinidades de contenido, porque ello implica tratar como idénticos procedimientos formales claramente diferentes. Así, identificar como un mismo tipo de subordinada (condicional) las tres variantes de (20) significa obviar que corresponden a patrones formales distintos, ya que (2ob) se asimila a las completivas (ensamble externo) y (20c) a las relativas (ensamble interno):

(20) a. Si me dieran permiso, lo haría.

b. En el caso de que me dieran permiso, lo haría.

c. En el momento en que me dieran permiso, lo haría.

Queda, en fin, determinar a cuál de los dos grupos corresponde (20a). Bello ( 1988 [ I 847]: $\$ 4$ I I) considera si un adverbio relativo ${ }^{16}$. En tal caso, la subordinada se obtendría por ensamble interno y, consecuentemente, tendría más similitudes con (20c) que con (2ob). Un argumento a favor de esta idea lo proporciona la íntima relación que este elemento tiene con la polaridad de la oración como marca de vericidad contingente. En tal caso, se trataría de un nexo que cumple una función interna en la subordinada, característica diferencial de los elementos relativos.

\section{REFERENCIAS BIBLIOGRÁFICAS}

Alarcos LloraCH, Emilio (I994): Gramática de la lengua española, Madrid: Espasa Calpe.

AlCina Franch, Juan y José Manuel BleCUA (1975): Gramática española, Barcelona: Ariel.

Alonso, Amado y Pedro HenríQuez Ureña (I97I [1935-1936]): Gramática castellana, Buenos Aires: Losada. 2 vols.

ARNAULT, Antoine y Claude LANCELOT (I754 [1660]): Grammaire générale et raisonnée, Paris: Prault. http://visualiseur.bnf.fr/Visualiseur?Destination=Gallica\&O=NUMM-84320.

ARNAUlT, Antoine y Pierre NICOLE (I992 [I662]): La Logique, ou L'art de penser (epíl. y notas Charles Jourdain), Paris: Gallimard. https://gallica.bnf.fr/ark:/ 2 I 48/bpt6k25788r/fr.image.

BELLO, A. (I988 [I847]): Gramática de la lengua castellana destinada al uso de los americanos, Madrid: Arco/Libros.

BlOOMFIELD, Leonard (1933): Language, New York: Holt.

\footnotetext{
${ }^{16}$ En esa misma línea, Rigau (1984) defiende la naturaleza adverbial de esa partícula en catalán a propósito de las subordinadas interrogativas indirectas y Haegeman (2010) propone un análisis de ascenso del nexo subordinante para las oraciones condicionales.
} 
BOSQUE, Ignacio (1984): "Sobre la sintaxis de las oraciones exclamativas", Hispanic Linguistics, I, pp. 283-304.

BOSQUE, Ignacio (dir.) (2004): Redes. Diccionario combinatorio del español contemporáneo, Madrid: SM.

BOSQUE, Ignacio y Violeta DEMONTE (dirs.) (I999): Gramática descriptiva de la lengua española, Madrid: Espasa Calpe. 3 vols.

BOSQUE, Ignacio y Javier GUTIÉRREZ-REXACH (2009): Fundamentos de sintaxis formal, Madrid: Akal.

BReSNAN, Joan (ed.) (1982): The Mental Representation of Grammatical Relations, Cambridge (MA): The MIT Press.

Breva-Claramonte, Manuel (1983): Sanctius' Theory of Language, Amsterdam: John Benjamins.

BRUCART, Josep Maria (I993): "Sobre la estructura de SComp en español”, en Amadeu Viana (ed.), Sintaxi. Teoria i perspectives, Lleida: Pagès, pp. 59-102.

BRUCART, Josep Maria y Ángel Jesús GALLEGO (2009): “L'estudi formal de la subordinació i l'estatus de les subordinades adverbials”, Llengua i Literatura, 20, pp. I39-I9I.

BRUCART, José María y Ángel Jesús GALLEGO (2016): “Aspectos formales e interpretativos de la subordinación adverbial”, en María Victoria Pavón Lucero (ed.), Las relaciones interoracionales en español, Berlin: De Gruyter, pp. I6I-I 99. https://doi.org/I0.1 5 I 5/9783 I I04292 I 3-006.

BRUCART, José María y Maria Lluïsa Hernanz (20 I 5): “Las posiciones sintácticas”, en Ángel Jesús Gallego (ed.), Perspectivas de sintaxis formal, Madrid: Akal, pp. 33-ıо9.

CHOMSKY, Noam (198I): Lectures on Government and Binding, Dordrecht: Foris.

CHOMSKY, Noam (1995): The Minimalist Program, Cambridge (MA): MIT Press.

CINQUE, Guglielmo y Luigi RIZZI (20 Io): “The Cartography of Syntactic Structures”, en Bernd Heine y Heiko Narrog (eds.), The Oxford Handbook of Linguistic Analysis, Oxford: Oxford University Press, pp. 51-65. https://doi.org/I0.1093/oxfordhb/9780199677078.013.0003.

CORDE = REAL ACADEMIA ESPAÑOLA: Banco de datos (CORDE) [en línea]. Corpus diacrónico del español. http://www.rae.es.

$C R E A=$ REAL ACADEMIA ESPAÑOLA: Banco de datos (CREA) [en línea]. Corpus de referencia del espanol actual. http://www.rae.es.

CRISTOFARO, Sonia (2003): Subordination, Oxford: Oxford University Press.

DOMINICY, Marc (1984): La naissance de la grammaire moderne. Langage, logique et philosophie à PortRoyal, Bruxelles: Mardaga.

DONZÉ, Roland (I970 [1967]): La gramática general y razonada de Port-Royal. Contribución a la historia de las ideas gramaticales en Francia, Buenos Aires: Eudeba.

ESPINOSA ELORZA, Rosa María (2016): "Los cambios en las fronteras entre relativos, interrogativos y conjunciones”, en María Victoria Pavón Lucero (ed.), Las relaciones interoracionales en español. Categorias sintácticas y subordinación adverbial, Berlin: De Gruyter, pp. I I-I 22. https://doi.org/ I0.1 51 5/9783II0429213-004.

FERNÁNDEZ RAMÍREZ, Salvador (I986 [195 I]): Gramática española, 2 a ed., Madrid: Arco/Libros. 5 vols.

FERnÁNDEZ SORIANO, Olga (I995): "Pronombres reasuntivos y doblado de clíticos”, en Patxi Goenaga (ed.), De Grammatica Generativa, Gasteiz/Donostia: Universidad del País Vasco / Diputación Foral de Gipuzkoa, pp. І о9-I 28. 
GARDINER, Alan H. (I95 I [1932]): The Theory of Speech and Language, 2. ${ }^{\mathrm{a}}$ ed., Oxford: Clarendon.

Gómez Hermosilla, José Mamerto (I 84I [1835]): Principios de gramática general, $3 \cdot{ }^{a}$ ed., Madrid: Imprenta Nacional.

GrafFI, Giorgio (200I): 200 Years of Syntax. A Critical Survey, Amsterdam: John Benjamins.

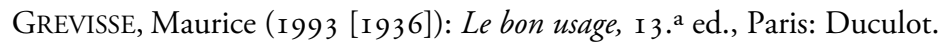

GuTIÉRREZ ORdóŃEZ, Salvador (I999): “¿Qué es una oración subordinada?”, en Jesús Fernández González, Carmen Fernández Juncal, Mercedes Marcos Sánchez, Emilio Prieto de los Mozos, Luis Santos Río (eds.), Lingüistica para el siglo XXI, Salamanca: Universidad de Salamanca, vol. I, pp. 49-72.

GutiéRREZ-REXACH, Javier (I999): "Spanish exclamatives and the interpretation of the left periphery”, en Yves D’Hulst, Johan Rooryck y Jan Schroten (eds.), Romance Languages and Linguistic Theory 1999, Amsterdam: John Benjamins, pp. I67-194. https://doi.org/10.1075/cilt.22 I.07gut.

HAEgEMAN, Liliane (2010): “The movement derivation of conditional clauses", Linguistic Inquiry, 4I(4), pp. 595-62 I. https://doi.org/IO.I I62/ling_a_ooo I 4.

Herling, Simon H. A. (I 82 I): "Über die Topik der deutschen Sprache”, Abhandlungen des Frankfurtischen Gelehrtenvereins für deutsche Sprache, 3, pp. 296-362.

Huddleston, Rodney y Geoffrey K. PUllum (2002): The Cambridge Grammar of the English Language, Cambridge: Cambridge University Press.

HumboldT, Wilhelm von (1836): Über der Verschiedenheit des menschlichen Sprachbaues und ihren Einfluss auf die geistige Entwicklung des Menschengeschleschts, Berlin: F. Dümmler.

JESPERSEN, Otto (1924): The Philosophy of Grammar, London: Georg Allen \& Unwin.

KAYNE, Richard (1976): "French Relative 'que”, en Marta Luján y Fritz Hensey (eds.), Current Studies in Romance Linguistics, Washington: Georgetown University Press, pp. 25 5-299.

LANGACKER, Ronald W. (1987-I99I): Foundations of Cognitive Grammar, Stanford: Stanford University Press. 2 vols.

LENZ, Rodolfo (1920): La oración y sus partes, Madrid: Centro de Estudios Históricos.

LOPE BlANCH, Juan Miguel (1979): El concepto de oración en la lingüistica española, México: El Colegio de México.

LOPE BlanCH, Juan Miguel (I984): “Despronominalización de los relativos”, Hispanic Linguistics, I, pp. 257-272.

MARTINET, André (1960): Élements de linguistique générale, Paris: Armand Colin.

MERCHANT, Jason (200I): The Syntax of Silence: Sluicing, Islands and the Theory of Ellipsis, Oxford: Oxford University Press.

MERCHANT, Jason (2004): “Fragments and ellipsis”, Linguistics and Philosophy, 27, pp. 66I-738.

MERCHANT, Jason (2018): “Ellipsis: A survey of analytical approaches”, en Jeroen van Craenenbroeck y Tanja Temmerman (eds.), The Oxford handbook of ellipsis, Oxford: Oxford University Press, pp. 19-45. https://doi.org/I0.1093/oxfordhb/9780198712398.013.2.

MUlLER, Claude (1996): La subordination en français, Paris: Armand Colin.

NARBONA, Antonio (1989-1990): Las subordinadas adverbiales impropias en español, Málaga: Ágora. 2 vols. 
PADLEY, George Arthur (1988): Grammatical Theory in Western Europe, I500-I700. Trends in Vernacular Grammar II, Cambridge: Cambridge University Press.

PARIENTE, Jean-Claude (1984): "Grammaire et logique à Port-Royal", Histoire, Épistemologie, Langage, 6(I), pp. 57-75. https://doi.org/I0.3406/hel.1984.1 I76.

PARIENTE, Jean-Claude (1985): L'analyse du langage à Port-Royal. Six études logico-grammaticales, Paris: Minuit.

PARSONS, Terence (1990): Events in the Semantics of English: A Study of Subatomic Semantics, Cambridge (MA): MIT Press.

PAVÓN LUCERO, María Victoria (20 I 2): Estructuras sintácticas en la subordinación adverbial, Madrid: Arco/Libros.

PlanN, Susan (1982): “Indirect Questions in Spanish”, Linguistic Inquiry, I3, pp. 297-3 I 2.

PlanN, Susan (1984): "Cláusulas cuantificadas”, Verba, I I, pp. Io I-I 28.

RAE I 928 = REAL ACADEMIA ESPAÑOLA (I928): Gramática de la lengua española, Madrid: Hernando.

RAE y ASALE 2009 = REAL ACADEMIA ESPAÑOLA y ASOCIACIÓN DE ACADEMIAS DE LA LENGUA ESPAÑOla (2009): Nueva gramática de la lengua española, Madrid: Espasa. 2 vols.

RAE y ASALE 2014 = REAL ACADEMIA ESPAÑOLA y ASOCIACIÓN DE ACADEMIAS DE LA LENGUA Española (20 14): Diccionario de la lengua española, 23. ${ }^{\mathrm{a}}$ ed., Madrid: Espasa. https://dle.rae.es/ [actualización en línea de 2017].

RIGAU, Gemma (I984): "De com si no es conjunció i d'altres elements interrogatius", en Joan Mascaró et al. (eds.), Estudis gramaticals I. Working Papers in Linguistics, Bellaterra: Universitat Autònoma de Barcelona, pp. 249-278.

Rodríguez Ramalle, Teresa María (2005): Manual de sintaxis del español, Madrid: Castalia.

Rojo, Guillermo (I978): Cláusulas y oraciones, Santiago de Compostela: Universidad de Santiago de Compostela.

RojO, Guillermo (1994): "Estado actual y perspectivas de los estudios gramaticales de orientación funcionalista aplicados al espańol", Verba, 21, pp. 7-23.

ROJO, Guillermo (2001): El lugar de la Sintaxis en las primeras Gramáticas de la Academia, Madrid: Real Academia Española. Disponible en http://www.rae.es.

RUIZ DE MENDOZA IBÁŇEZ, Francisco José (200I): "Lingüística cognitiva: semántica, pragmática y construcciones", Círculo de Lingüistica Aplicada a la Comunicación, 8. http://www.ucm.es/info/ circulo/no8/ruiz.htm.

SÁNCHEZ de LAS BROZAS, Francisco (1976 [ 5 87]): Minerva o De la propiedad de la lengua latina (trad. Fernando Riveras Cárdenas), Madrid: Cátedra.

SECO, Manuel (1974): Gramática esencial del español, Madrid: Aguilar.

TRUJILlO, Ramón (I990): "Sobre la supuesta despronominalización del relativo", ELUA, 6, pp. 23-45. https://doi.org/I0.I4198/eluai990.6.02. 